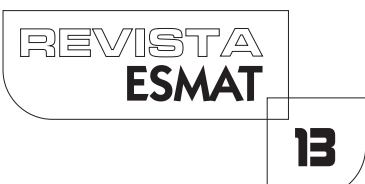

\title{
INQUÉRITO POLICIAL BLACK BLOC: INSTRUMENTO DE CRIMINALIZAÇÃO DE UM MOVIMENTO SOCIAL
}

BLACK BLOC POLICE INVESTIGATION: MECHANISM OF SOCIAL MOVEMENT CRIMINALIZATION

\section{Bruno Almeida de Oliveira}

Especialista em Direito Penal Econômico pelo Instituto de Direito Penal Económico Europeu da Universidade de Coimbra/IBCCRIM (20 I 5) e especialista em Direitos Fundamentais pelo "lus Gentium Conimbrigae", da Universidade de Coimbra/IBCCRIM (2017); especialista Direito Penal e Criminologia pela Uninter (2017); assistente jurídico de desembargador do Tribunal de Justiça de São Paulo.

\section{RESUMO}

Trata-se de pesquisa bibliográfica documental a partir de mote, caso concreto, em perspectiva de "law in action", apreciável em pesquisa jurídica, inserida nas grandes áreas dos Direitos Constitucional e Penal, tema Criminalização dos Movimentos Sociais. $\bigcirc$ objetivo geral é ofertar válida resposta ao problema: O Inquérito Policial nº 0 I , de 2013 , o "inquérito black bloc", ostentou características de criminalização de movimentos sociais? A hipótese é a resposta afirmativa, confirmada ao fim deste estudo.

PALAVRAS-CHAVE: Movimento; Social; Criminalização; Inquérito; Blac-Bloc.

\section{ABSTRACT}

It is bibliographic research inserted in the great areas constitutional right and penal right, subject criminalization of the social movements. The general objective is to offer a valid answer to the problem: the police investigation 0I/2013, the "black bloc police investigation", has characteristics of social movements criminalization? The hypothesis is the affirmative answer, confirmed at the end of this study.

KEYWORDS: Movement; Social; Criminalization; Investigation; Black-bloc. 


\section{INTRODUÇÃO'}

Este trabalho constitui o resultado de pesquisa bibliográfica documental nas grandes áreas dos Direitos Constitucional e Penal, tema Criminalização dos Movimentos Sociais, dividido em quatro itens principais.

$\bigcirc$ objetivo geral é ofertar válida resposta ao problema da pesquisa: $\bigcirc$ Inquérito Policial $\mathrm{n}^{\circ} \mathrm{OI}$, de 2013, o "inquérito black bloc", ostentou características de criminalização de movimentos sociais? A hipótese é a resposta afirmativa.

No item I, foi abordado, a partir da versão oficial, o arquivamento do referido expediente administrativo, que tramitou no Departamento Estadual de Investigações Criminais (DEIC), da Polícia Civil de São Paulo, popularmente conhecido como "inquérito black bloc". Um mote, forma de aproximação à problemática com base em caso concreto e realce a perspectivas e tensões da "law in action", bem apreciáveis em pesquisa jurídica (CARVALHO, 20 I3, p. 52)

Em contraponto, o item I.I versou sobre críticas da sociedade civil as quais vislumbravam e vislumbram no cogitado inquérito policial características e objetivos outros, para além dos quadrantes da legalidade estrita e do estado democrático de direito.

Sobretudo porquanto não voltado à investigação de atos e sujeitos concretos, individualizados (direito penal do fato), mas de um modo ser, geral e genérico, "ser ou não ser black bloc", ou "ser ou não ser manifestante" (direito penal do autor), e que repercute, em ápice repressivo, na denominada Criminalização dos Movimentos Sociais.

Daí o interesse de serem esmiuçados, no item 2, quadro geral sobre movimentos sociais, características, importância e objetivos, assim como o fenômeno da sua criminalização, descrito na sequência, no item 3 .

Por fim, no item 4, a retomada do problema de pesquisa, considerações com pretensão crítica (NOBRE, 2008, p. I 7) ² e resposta: O Inquérito Policial nº 01 , de 20 I 3, o "inquérito black bloc", ostentou características de criminalização de movimentos sociais. Confirmada a hipótese, pelas razões lá alinhavadas.

\section{O INQUÉRITO POLICIAL Nº 0I, DE 2013:VERSÃO OFICIAL}

Ano passado, o Jornal Folha de São Paulo noticiou o arquivamento do Inquérito Policial n 01 , de 2013, do Departamento Estadual de Investigações Criminais de São

\footnotetext{
' Em razão do vínculo que o articulista ostenta com o Estado de São Paulo, por desempenhar função pública no Tribunal de Justiça, convém ressalvar que este trabalho constitui apreciação doutrinária fundamentada, e não crítica estéril às autoridades constituídas e aos atos da Administração, tudo conforme art. 242, I, da Lei Estadual n |0.268, de I96 I .

Dois são os pressupostos do "modelo crítico": I . Apreensão da realidade e diagnóstico do tempo presente, e 2. Identificação de possibilidades que permitam o alcance da emancipação.
} 
Paulo, da Polícia Civil, cujo objetivo era a investigação de múltiplas condutas atribuídas a indivíduos suspeitos de serem mascarados adeptos da denominada "Tática Black Bloc" (SOLANO; MANSO; NOVAES, 2014, p. 17).

O expediente, "mãe" de outros dezesseis com semelhantes objetos, decorreu de trabalho conjunto de membros de força-tarefa composta por Polícias civil e militar e Ministério Público, criada para coibir "minorias de baderneiros", como declarou o Secretário de Justiça Estadual à época (TUFANO, 20|4).

Ainda de acordo com a reportagem, Inquérito Policial n ${ }^{\circ} 01$, de 2013 , foi instaurado por "pressão do governo" após registro de diversos boletins de ocorrência sobre crimes praticados no desenrolar de manifestações públicas reivindicatórias ocorridas em São Paulo, a partir de junho de 2013, sobranceiramente motivadas por históricos déficits sociais (SCHERER-WARREN, 20 I 4, p. 419).

A tramitação transcorreu por cerca de dois anos, sob segredo de justiça. Foram mais de trezentos depoimentos e/ou oitivas, prisões cautelares, quebras de sigilos telefônico e cibernético materializados em centenas de atos de polícia judiciária constantes em dezessete volumes.

Entretanto, conforme a autoridade policial responsável, deu-se arquivamento sem indiciamentos ante a impossibilidade de individualização de condutas, "até para não se cometer nenhuma injustiça".

promotor de justiça oficiante, por sua vez, afirmou que a expectativa era denunciar "black blocs" por associação criminosa, crime previsto no art. 288 do Código Penal ${ }^{3}$. À semelhança do que supunha o diretor do DEIC à época da instauração do Inquérito Policial: "a intenção é descobrir quem são eles são, de onde vêm. Eles são uma organização criminosa? Sim. E nossa função é provar isso" (FOLHA DE SÃO PAULO, 2013).

Nada obstante, o inquérito não teve o sucesso esperado, porquanto culminou em arquivamento, consoante a versão oficial. Em suma, infrutífera mobilização de recursos públicos e de aparato estatal das agências criminais.

\section{I.I O "inquérito black bloc": versão latente}

Paralelamente, outras facetas relacionadas ao Inquérito Policial $\mathrm{n}^{\circ} 0 \mathrm{I}$, de 2013 , foram suscitadas pela sociedade civil, aqui, reputadas "latentes". À semelhança de conhecida construção teórica sobre fins oficiais e latentes da pena, assunto deveras diverso, porém com lógica perfeitamente aplicável ao abordado doravante (CIRINO, p. 428-429).

\footnotetext{
${ }^{3}$ Art. 288. Associarem-se 3 (três) ou mais pessoas, para o fim específico de cometer crimes (...).
} 
De partida, dois dados preliminares. A primeira é a atribuição de número "0 I " a um inquérito policial instaurado em meados de 2013; a segunda, a popular forma de denominá-lo, não pela impessoal numeração oficial, mas pela indicação de sujeito criminalizado concreto, o que bem realçaria seu objetivo. Daí "inquérito black bloc".

No que de imediato releva, alegam seus críticos tratar-se de inquérito policial permeado de ilegalidades que deveriam ensejar pronto arquivamento (CONECTAS, 20|4), coisa acontecida, todavia, superados mais de dois anos de tramitação. Dentre elas, afirmam não constituir expediente administrativo preparatório a ação penal, destinado à obtenção de elementos de informação sobre autoria e materialidade de infrações penais sobre sujeito e fatos concretos, individualizados ( $N U C C l, 2008$, p. 70), como é da praxe da estrita legalidade e do estado democrático de direito.

Mas, sim, instrumento de identificação, fichamento e monitoração de pessoas, meros suspeitos "black blocs", até mesmo em redes sociais (CARVALHO, 20|4), consoante dinâmica repressiva particular.

Com efeito, primeiramente, as polícias promoveram "prisões para averiguação" (IBCCRIM, 20 I3, p. I) em diversas manifestações públicas, com condução de pessoas a Delegacias de Polícia e identificação. Por exemplo, no emblemático |4/6/20 I3, em que duzentas e trinta e dois manifestantes foram conduzidos a Delegacias de Polícia em São Paulo e apenas 4 deles foram presos.

Aí, sem sombra de dúvidas, ressabida e insuperável "prática que afronta a Constituição Federal, mas suficiente à temporária neutralização de seus alvos" (OLIVEIRA, 2016, p. I| 5).

Em prosseguimento, os "suspeitos" passaram a ser intimados para declarações em inquéritos policiais instaurados, dentre eles, o Inquérito Policial $\mathrm{n}^{\circ} \mathrm{OI}$, de 2013. No ponto, essencial examinar o teor das perguntas constantes do "Termo de Declarações" - padrão deste (REVISTAFÓRUM, 20 | 4):

- Já participou de outras manifestações?

- Qual seu objetivo nestas manifestações?

- Participou de outros eventos que resultou quebra-quebra?

- Como estava trajado no dia da manifestação?

- A senhora tem perfil no facebook ou outro meio similar de comunicação disponível na internet, redes sociais ou e-mail?

- Qual o nome que a senhora usa nas redes sociais, ou seja, como é encontrado e qual o endereço de e-mail que utiliza?

- Asenhora é uma "black bloc"?

- Por quais motivos?

- Qual é o objetivo e o propósito destas pessoas (black blocs)?

- Como funcionam as manifestações?

- Quem chama para participar e como se dá esse chamamento?

- Revele detalhes desses indivíduos que durante as manifestações ocorridas nos últimos meses se misturam aos demais manifestantes e num ato de vandalismo destroem a 
cidade, danificando o patrimônio público e privado?

- Por que tais pessoas agem dessa forma?

- Quem organiza as manifestações praticadas pelos black blocs?

- Existe liderança entre os senhores?

- Quem determina que seja feito dessa forma?

- Conhece alguns manifestantes?

- Quantas pessoas estavam com a senhora no dia em que foi detida/conduzida ao DP?

- Sempre participa de manifestações?

- Com que frequência?

- Existe algum partido político envolvido ou que custeia o movimento?

-Éfiliado a algum partido político? Qual?

- Existe algum lugar onde os senhores se concentram para deliberar sobre as ações do grupo?

- Quem coordena as reuniões? Ocorrem com frequência?

- Quem comandava o movimento no dia em que a senhora foi detida? Existia uma liderança? Qual?

- Quem determina o que deve, ou não, ser realizado?

- Que indagada sobre a reportagem postada na Revista Época de $|1 /||/ 20| 3$ ?

- Já esteve no sítio mencionado na reportagem?

- Recebeu algum tipo de treinamento para o confronto com policiais?

- Na data em que foi detida, presenciou se haviam integrantes dos black blocs entre os manifestantes?

Como se vê, a maioria das indagações não se refere a fato determinado, mas uma qualidade, "ser ou não ser black bloc", assim como supostas circunstâncias daí derivadas. Aquela característica típica de direito penal do autor, repressivo, estigmatizador e baseado em pressuposta periculosidade do agente; reverso do esperado direito penal do fato, tônico do estado democrático de direito (ZAFFARONI, PIERANGELI, 20 I I , p. I I0).

Refundindo-se, assim, quem sabe, lógica histórico-institucional brasileira no melhor estilo DOI-CODI, outrora, destinada à contenção de inimigo interno-subversivo (ARNS, 1985, p. 4).

Aquela mesma peculiar ressonância da doutrina de Segurança Nacional no Brasil, fundada em obediência, disciplina e fidelidade, identificado o conflito como sintoma de patologia, que merece ser tratada; atos de dissenso político e reivindicação à delinquência (BRITO, 20 I4, p. 3).

Por isso, prosseguem os críticos do Inquérito Policial n 01 , de 2013, a afirmar consubstanciar, em realidade, peça de engrenagem da conjuntura atual de uma "estratégia do medo" para a prática de prisões arbitrárias (ANISTIA INTERNACIONAL, 20 I4), de "truculência e violência estrutural das polícias" (IBCCRIM, 20I3), manifesta 
em múltiplos atos concretos de agressões físicas e morais a manifestantes antes, durante e após manifestações públicas, noticiadas, reportadas e filmadas pela imprensa (CONECTAS, 2013).

Argumentativamente, assim, o constituiria, em verdade, não um fracasso, em razão do arquivamento sem indiciamentos (versão oficial); mas um grande sucesso, representativo de prática de atos de identificação, fichamento e monitoração de três centenas de "suspeitos", típico de época de ditadura, em tempos de declarado estado democrático de direito (versão latente).

Sobre assim ser, não soaria leviano concluir ter tudo objetivo principal a contenção do mascarado, considerado mesmo inimigo pelas agências criminais, consoante mais de cinco mil agentes de segurança pública entrevistados em pesquisa de abrangência nacional (GETÚLIO VARGAS, 20 | 4).

Tornando-se, assim, talvez, letra morta direitos e garantias fundamentais:

Art. 5. $^{\circ}$ Todos são iguais perante a lei, sem distinção de qualquer
natureza, garantindo-se aos brasileiros e aos estrangeiros
residentes no País a inviolabilidade do direito à vida, à liberdade,
à igualdade, à segurança e à propriedade, nos termos seguintes:
$[\ldots]$
IV - é livre a manifestação do pensamento, sendo vedado o
anonimato;
$[\ldots .$.
VIII - ninguém será privado de direitos por motivo de crença
religiosa ou de convicção filosófica ou política, salvo se as
invocar para eximir-se de obrigação legal a todos imposta e
recusar-se a cumprir prestação alternativa, fixada em lei; $[\ldots]$

IX - é livre a expressão da atividade intelectual, artística, científica e de comunicação, independentemente de censura ou licença;

$[\ldots]$

$\mathrm{XVl}$ - todos podem reunir-se pacificamente, sem armas, em locais abertos ao público, independentemente de autorização, desde que não frustrem outra reunião anteriormente convocada para o mesmo local, sendo apenas exigido prévio aviso à autoridade competente.

Quadro, em síntese, convergente para a constatação de um pano de fundo mais amplo, não pontual ofensa a direitos fundamentais deste ou daquele manifestante, unitariamente considerados, mas efetiva Criminalização dos Movimentos Sociais (MACRUZ, 20|4).

Mas para que se possa abordar tal fenômeno com alguma plausibilidade teórica, convém, por primeiro, esmiuçar características gerais dos seus destinatários, os movimentos sociais, desde já sem perder de vista o central: reputá-los lócus legítimo de 
INQUÉRITO POLICIAL BLACK BLOC: INSTRUMENTO DE CRIMINALIZAÇÃO DE UM MOVIMENTO SOCIAL

manifestação de discursos, "sine qua non" a uma república fundada no pluralismo político (MENDONÇA, 20। 5, p. 66).

\title{
2 MOVIMENTOS SOCIAIS
}

Numa das mais célebres passagens da história da filosofia do direito, IHERING inicia seu pequeno grande livro sobre a luta do direito com a observação de que

\begin{abstract}
A paz é o fim que o direito tem em vista, a luta é o meio de que se serve para consegui-lo e que todos os direitos da humanidade foram conquistados na luta, todas as regras importantes do direito devem ter sido, na sua origem, arrancadas àquelas que a elas se opunham (IHERING, 2009, p. 19).
\end{abstract}

Sem sombra de dúvidas, um belíssimo grito de emancipação, adotado, aqui, como preambular aproximação à temática que anima este tópico, quais sejam, movimentos sociais, características importância e objetivos.

Os movimentos sociais constituem conjunto de práticas sociais e de ideias (rectius: uma práxis), com caráter político, motivadoras ou fundamentadoras do agir de atores sociais oriundos de diferentes estratos da coletividade, unidos por uma identidade comum.

Podem ter caráter ativo, passivo ou reativo, imbricados num plano maior, de lutas sociais cíclicas, não institucionalizadas, e que se concretizam mediante demandas, eventualmente materializadas em reivindicações, na ação coletiva (GOHN, 2000, p. 12-13).

Trata-se de um novo sujeito histórico coletivo, que se "articula em torno do sofrimento - às vezes centenário - e das exigências cada vez mais claras de dignidade, participação, de satisfação mais justa e igualitária das necessidades humanas fundamentais de grandes parcelas sociais excluídas, dominadas e exploradas da sociedade" (WOLKMER, 20 I 5, p. 48).

Numa sociedade plural, como é a brasileira, apresentam-se sob diversos signos socioculturais, como da população negra, feministas e ecologistas. Cenário que, na prática, constitui um desafio para vivência e convivência deles, notadamente ante a busca da concretização das reivindicações, por vezes, divergentes, quando não contraditórias (CARDOSO, 1994, p. 88).

Por isso, a assunção de objetivos com características mais universalizáveis, como "lutar por um sistema de governo mais democrático, onde o espaço aberto para as reivindicações seja maior e os instrumentos de decisão estejam sob maior controle da sociedade civil" (CARDOSO, 2008, p. 348-349) constituem desafios atuais sobre o tema.

Nessa ordem de ideias, propaga-se a busca de uma conexão entre "diversidade 
identitária e transversalidade de demandas" (SCHERER-WARREN, 2006, p. I09), potencialmente hábil à somatória de forças, ao incremento da visibilidade e, por conseguinte, do impacto das ações dos coletivos na esfera pública, com maior número de conquistas. Um exemplo característico das denominadas Redes de Movimentos Sociais (SCHERER-WARREN, 2006, p. I I3).

A realidade e a relevância deles são indeléveis no Brasil, por exemplo, a Constituição Federal, de 1988 (SILVA, 2007, p. 174). Por evidente, nada há de ufanismo nisso; basta uma mera constatação da história, o "profeta com olhar voltado para trás", no dizer do poeta (GALEANO, 2006, p. 9).

Assim, sustenta-se que "os direitos humanos têm sido, ao longo da história, uma construção dos múltiplos movimentos sociais, e não o resultado de um ordenamento jurídico ou o efeito de uma declaração" (VIOLA, 2008, p. 4I).

Consoante especialista no tema, é possível traçar-se a trajetória dos movimentos sociais no Brasil, esquematicamente, em três ciclos, compreensivos "de lutas pela democratização do país e serviços públicos (1972-1984), institucionalização dos movimentos (1985-1989) e emergência de novos atores e desmobilização dos movimentos populares urbanos ( I992- 1997)" (GOHN, I997, p. 378-383).

Exemplo concreto citado pela autora em relação ao derradeiro ciclo, para melhor entendimento: Movimento Nacional Contra Corrupção (1992), articulador da renúncia-impeachment do presidente Collor de Mello.

Malgrado a mudança de demandas, perfis de militantes e mecanismos de lutas sociais, sobretudo com o advento das Organizações Não Governamentais (ONGs) na década de noventa, os movimentos sociais ganharam importante papel de busca da "democratização das relações sociais dentro da sociedade civil, através da redefinição de papéis, normas, identidades (individuais e coletivas), conteúdo e modos de interpretação de discursos existentes nesta esfera" (PEREIRA, 20I5, p. 79), num "processo de autocrítica permanente". Novamente, para o alcance de metas como dignidade da pessoa humana e cidadania, fundamentos da república (PINASSI, 2008, p. 7).

Os movimentos sociais também encamparam pretensões de ampliação de mecanismos de participação do povo na vida política, às vezes, no "tranco da pressão social" (ABEL, 2008, p. 28), numa "intromissão legítima", tendentes à correção de distorções em processos decisórios políticos governamentais marcados, v.g, por excessiva influência do poder econômico e de clientelismos partidários nas decisões políticas concernentes às finanças públicas (YAMAUTI, 200 I , p. 247).

Medidas as quais, evidentemente, ostentam intrínseca correlação com democracia, para além do marco representativo, mas da perspectiva participativa; pela cidadania em sua maior amplitude possível no domínio das decisões estatais, sobretudo o controle delas (TOURAINE, 1996, p. 4I-42). Em suma, efetiva primazia na condução da coisa pública (DÍAZ, 1998, p. |44).

Até mesmo, se caso, com a possibilidade de amplamente se manifestarem nas ruas, exemplo mais característico da esfera pública, quanto a desconformismos relativos à 
condução de quaisquer assuntos afetos às incumbências estatais, como políticas públicas e serviços públicos. Algo que não pode ser obliquado sobre pretensão alguma de contenção de supostos inimigos estatais.

Vale lembrar que o conflito legítimo permite aos cidadãos a luta pela construção da comunidade política (CHUERI, 20 I4, p. 30); fortalece a democracia, e não a degrada, como se sustenta em voz corrente.

Por consubstanciarem os movimentos sociais legítimos, ou seja, aqueles que não se amoldam a situações excepcionais proscritas na Constituiçã̃o Federal, v.g, constituição de grupos políticos armados, privilegiados instrumentos de mobilização social e de desenlace dos objetivos declarados desta república, devem ser protegidos pelo Estado, e não criminalizados, como, infelizmente, tem acontecido neste País.

\section{CRIMINALIZAÇÃO DOS MOVIMENTOSSOCIAIS}

Conceitua-se a Criminalização dos Movimentos Sociais "em enquadramento, em determinados tipos penais, de condutas próprias de movimentos coletivos que reivindicam direitos, e no que tange ao autor, da individualização e da estigmatização de sujeitos que integram tais movimentos (ou defensores e militantes que os apoiam) como associados ao estereótipo comum 'do bandido'" (GIAMBERARDINO, 20।4, p. 654655).

Agir fundado em estruturas, finalidades e formas de coerção detrimentosas de debate e/ou embate legítimos na esfera pública, em prol de disseminado sentimento de segurança, indelével marca histórica atribuída a movimentos sociais (MORAES, 20 I 3, p. 4), sempre e sempre associada a demandas punitivas (MOURA MASIERO, 20 I2, p. 148).

A interlocução entre o povo, donde o poder emana, e o Estado é feita pelas agências criminais, e não pelos órgãos efetivamente representativos do poder estatal (FOWLER, 2000, p. 5.320).

Sinais evidentes, tudo leva a crer, de pleno vigor, da Doutrina da Segurança Nacional no Brasil, a qual, em passado recente, inculcava a outros inimigos - subversivo, terrorista ou comunista - aquilo que se atribui ao vândalo, mascarado e anarquista nos dias atuais (VIOLA, 2014, p. 92), cujas raízes deitam no mito da ordem pública, reconstruído constantemente no século passado para a subsistência de permanências autoritárias (PEDROSO, 2005, p. 91 ).

Consequências imediatas de um regime político, na prática, não plural, modulado por aversões a conceber o outro como outro (SILVA FILHO, 20 I I, p. I23). E mais, jungido a "um bloqueio seletivo do acesso à legitimidade pública, uma questão central da construção democrática, que continua a desenhar a face autoritária do sistema político brasileiro" (FELTRAN, 2007, p. I I 2).

A repressão estatal pura e simples dos movimentos sociais, pela força, mormente das agências criminais, ironicamente passa a ser considerada consequência da 
impossibilidade do enquadramento de condutas de protesto, tuteladas pela Constituição Federal a categorias jurídico-penais democráticas atuais (PRADO, 20 I 5, p. 256-257).

Mesmo não tendo as lutas sociais atuais sintonia com as das décadas recentes de anos de chumbo, orientadas para a busca de tomada do poder contra um opressor "establishment"(PRADO, 20I5, p. 256-257).

O mesmo autor sustenta a necessidade de imposição de constrangimentos teóricos às generalizadas tentativas estatais de contenção de inimigos, que, usualmente, se espraia para não inimigos.

No específico caso das manifestações públicas reivindicatórias, condizente com a impossibilidade (em regra) de incriminação de atos preparatórios de crimes e a recondução de condutas relacionadas à "segurança nacional" a um bem jurídico constituem intransponíveis óbices à criminalização em questão.

Soçobrando-se, pois, fundamentos jurídico-legais ainda utilizados nos dias correntes para autorizar ou ratificar prisões de manifestantes com base na Lei Federal n 7. 170, de 1983, a Lei de Segurança Nacional, como abordado precedentemente. Agir, aliás, distante do marco constitucional da lesividade (D'ÁVILLA, TANGERINO, CARVALHO, 2012, p. 10-15).

E, no que principalmente releva este estudo, a associação da resistência, de "práxis contra hegemônica" (CELOS, 2005, p. 133) de mobilização social - que não significa condescendência ao quebra-quebra, como enfatizado na introdução - às costumeiras assimilações de manifestantes a baderneiros, membros de associação criminosa.

Até porque, na prática, violência, truculência e violação de direitos humanos, em contextos de manifestações públicas reivindicatórias, recaíram sobre todos, black blocs (inimigos declarados) e não black blocs (sociedade civil como um todo):

Para garantir o consenso em torno das políticas neoliberais, o Estado lança mão dos recursos ideológicos e apresenta os trabalhadores, em sua luta de resistência, como baderneiros, formadores de quadrilha, que insistem em perturbar a ordem ou não colaboram com os esforços da nação para superar a crise econômica. Apesar da regularidade dos pleitos eleitorais, os governos, em geral, têm aumentado a violência contra os trabalhadores e tratado suas mobilizações como casos de polícia e enquadrado os manifestantes no crime de formação de quadrilha, de acordo com a Lei $n^{\circ}$ 12.850, sancionada pela presidente Dilma Rousseff, em 02 de agosto de 2013. Embora o enquadramento de manifestantes e grevistas na Lei $n^{\circ}$ I2.850/20I3 e na Lei de Segurança Nacional tenha sido amplamente repudiado, o Estado manteve o discurso de manutenção da ordem e proteção do patrimônio público, afirmando que somente toleraria manifestações pacíficas. E os abusos continuaram, conforme denúncias de várias entidades 
de proteção dos direitos humanos, desde junho de 2013 foram realizadas cerca de 200 prisões arbitrárias e mais de 10 mortos pela polícia em ação contra as manifestações populares (SILVA, 2015, p. 396/397).

\section{I Casos Concretos}

Consoante a literatura, a Criminalização dos Movimentos Sociais fica evidenciada, entre outros, em dois documentos sobre investigações de efetivos, um da sociedade civil e outro de órgão estatal.

O primeiro é o "Relatório de Casos Exemplares" elaborado pelo Movimento Nacional de Direitos Humanos (MOVIMENTO NACIONAL DE DIREITOS HUMANOS, 2006), apresentado em outubro de 2006 em audiência pública na Organização dos Estados Americanos (OEA). Silva Filho (2008, p. 61 ) aborda sete casos, a maior parte deles sobre líderes de movimentos sociais, acusados de práticas de diversos crimes, como incitação ao crime e à quadrilha, considerados subterfúgios para contenção deles.

Emblemático é o do juiz de direito Jorge Moreno, do Maranhão, atuante na defesa dos direitos humanos. Foi aposentado de forma compulsória pelo Tribunal de Justiça daquele Estado, por praticar ditos atos de proselitismo político, decisão mantida pelo Conselho Nacional de Justiça (CONSELHO NACIONAL DE JUSTIÇA, 20 I3).

O segundo é o Relatório de Comissão do Conselho de Defesa dos Direitos da Pessoa Humana, da Secretaria Especial dos Direitos Humanos da Presidência da República, que contemplou investigações de denúncias de Criminalização dos Movimentos Sociais do Rio Grande do Sul a partir de iniciativas de agentes do Tribunal de Justiça, do Ministério Público e da Brigada Militar (CONSELHO NACIONAL DOS DIREITOS HUMANOS, 2009).

A conclusão, ainda que manifesta na linguagem, como sempre, "terreno pantanoso", é aterradora: "fica claro para os membros da Comissão Especial que realmente existem indícios da Criminalização dos Movimentos Sociais do campo e da cidade por parte dos poderes locais".

\section{CONCLUSÃO}

Este trabalho foi o resultado de pesquisa bibliográfica documental nas grandes áreas dos Direitos Constitucional e Penal, tema Criminalização dos Movimentos Sociais - direito em quatro itens, concebido a partir de um mote, o Inquérito Policial no 01 , de 2013, do DEIC, da Polícia Civil de São Paulo, dito "inquérito black bloc".

Nos tópicos anteriores foivisto que:

I. Após mais de dois anos de tramitação, ocorreu o arquivamento do referido Inquérito Policial, sob justificativa oficial de não individualização de condutas - item I; 
2. Houve, porém, desde a instauração, denúncias diversas da sociedade civil a sustentarem tratar-se tal Inquérito Policial, em verdade, na forma e no conteúdo, instrumento de investigação de pessoas, meros supeitos "black blocs" (direito penal do autor) - arbitrário, estigmatizador, e não de fatos concretos - legal, democrático (direito penal do fato) - item I . I ;

3. Esse expediente seguiu o influxo de prisões arbitrárias, violência e violação de direitos humanos pelas polícias, em contextos de manifestações públicas reivindicatórias. E, assim, evidenciando ilícita, irregular e inconstitucional identificação, fichamento e monitoração de pessoas, prática retrógrada e de estado de exceção - item I . I ;

4. Daí a plausível disparidade entre insucesso (versão oficial) e sucesso (versão latente) do Inquérito Policial n 0I, de 2013, a partir do seguinte ponto de vista: desde o início, era previsível a impossibilidade de individualização de condutas, o que afastaria a possibilidade de prosseguimento de ações penais contra "black blocs", mesmo em tempos atuais repressivos. Assim, finalidades outras, identificação, fichamento e monitoração de pessoas, almejadas desde o início, foram devidamente alcançadas, a atrair a ideia de sucesso.

5. Os movimentos sociais constituem, historicamente, principal instrumento de conquista de direitos, obtidos ao longo da história brasileira - item 2;

6. São as atuações desses privilegiados atores sociais fundamentais pedras de toque do estado democrático de direito, da cidadania, da dignidade da pessoa humana, do pluralismo político e da democracia participativa - item 2;

7. Existe tendência no Brasil à criminalização de movimentos sociais, em detrimento daqueles vetores inerentes ao estado democrático de direito; em prol de suposta necessidade difusa de segurança, que justificou e justifica pura e simples repressão estatal - item 3;

8. Consiste a legítima mobilização social - e não mero "quebra-quebra" - reforço à democracia, e não estorvo - item 3;

9. Existem casos concretos reportados de criminalização de movimentos sociais, ou seja, o fenômeno é real, não é lucubração ou que o valha;

10. $O$ teor das perguntas feitas aos investigados Inquérito Policial nº 0 , de 2013, denota claramente que o intuito era investigação de pessoas, e não de pessoas concretas por fatos concretos.

Isso observado, calha retomar o problema da pesquisa: o Inquérito Policial nº 0 I, de 2013, o "inquérito black bloc", ostentou características de criminalização de movimentos sociais?

Concluo: Pelas razões acima enunciadas, o Inquérito Policial nº 01 , de 2013, o "inquérito black bloc", ostentou características de criminalização de movimentos sociais. Fica confirmada a hipótese. 


\section{REFERÊNCIAS}

ABEL, Marisa. Rebeldes com causa. No rastro da Operação Satiagraha. Revista Artigo $5^{\circ}$. Associação Cultural Artigo 5․ Delegados de Polícia Federal pela Democracia, vol. 3, p.26-29, jul./ago. 2008.

AFONSO DA SILVA, José. Poder Constituinte e Poder Popular. São Paulo; Malheiros Editores, 2007.

ANISTIA INTERNACIONAL. Disponível em: <https://anistia. org.br/campanhas /brasil-chega-de-bola-fora/>. Acesso em 17 de agosto de 2017.

AVRITZER, Leonardo. Disponível em https://www.cartacapital.com.br/sociedade/oque-as-manifestacoes-no-brasil-nos-dizem-1313.html. Acesso em 17 de agosto de 2017.

BONAVIDES, Paulo. Teoria constitucional da democracia participativa: por um direito constitucional de luta e resistência por uma nova hermenêutica por uma repolitização da legitimidade. São Paulo: Malheiros, 2003.

CARDOSO, Ruth Corrêa Leite. A trajetória dos movimentos sociais. In: DAGNINO, Evelina (org.), Anos 90: política e sociedade no Brasil. São Paulo: Brasiliense, 1994.

- Movimentos sociais urbanos: balanço crítico. In: SORJ, B., and ALMEIDA, MHT. (Org). Sociedade política no Brasil pós-6I. Rio de Janeiro: Centro Edelstein de Pesquisas Sociais, 2008.

CARVALHO, Salo de. Como não se faz um trabalho de conclusão de curso. São Paulo: Saraiva, 2013.

CELOS, Jeferson Fernando. A atuação dos movimentos sociais populares que lutam pela terra, a partir de suas várias implicações com o direito. Revista de Estudos Jurídicos UNESP, Franca, v. I0, n. | 4, p. |29- I 51, jan./dez. 2005.

CHUEIRI, Vera Karam de. República, democracia e protestos. MPD Dialógico: Revista do Movimento Ministério Público Democrático, São Paulo, n. 4l, p. 29-30, fev. 2014 .

CONECTAS. Disponível em http://www.conectas.org/pt/acoes/justica/noticia/relatosde-vitimas-de-repressao-a-marcha-de-13-6-sugerem-undefinedemboscadaunde fined. Acesso em 17 de agosto de 2017. 
CONSELHO NACIONAL DEJUSTIÇA. Disponível em http://www.cnj.jus.br/noticias /cnj/59876-cnj-mantem-aposentadoria-compulsoria-de-juiz-decretada-pelo-tjma. Acesso em 17 de agosto de 2017.

CONSELHO NACIONAL DOS DIREITOS HUMANOS. Disponível em http://www.sdh.gov.br/sobre/participacao-social/cndh/resolucoes/2009/resolucaono-06_aprovacao-relatorio-criminalizacao-movimentos-sociais/view. Acesso em 17 de agosto de 2017.

D'ÁVILLA, Fábio Roberto; TANGERINO, Davi de Paiva Costa; CARVALHO, Salo. O Direito Penal na "luta contra o terrorismo". Sistema Penal \& Violência, Porto Alegre, v. 4, n. I, p. I-2 I, jan./jun. 20 I2, p. I0/I 5. Disponível em http:/revistaseletronicas.pucrs. br/ojs/index.php/sistemapenaleviolencia/article/view/I I 286. Acesso em 4 dez. 20 I 5.

DÍAZ, Elías. Estado de derecho y sociedad democrática. Madrid: Taurus, 1998.

FELTRAN, Gabriel de Santis. Vinte anos depois: a construção democrática brasileira vista da periferia de São Paulo. Lua Nova, São Paulo, 72: 83-1 |4, 2007, p. II2, disponível em: <http://www.scielo.br/pdf/n/n72/a04n72.pdf.> Acesso em: 6 dez. 2015.

FERRAZ. Lucas. Disponível em http://www I folha.uol.com.br/cotidiano/20 I 6/0 I/I73 3 I I I-principal-investigacao-sobre-black-blocs-termina-sem-acusar-ninguem.shtml. Acesso em 17 de agosto de 2017.

FOLHA DE SÃO PAULO. Disponível em http://wwwl.folha.uol.com.br/cotidiano /20 I3/I 0/I 357784-black-blocs-sao-organizacao-criminosa-diz-diretor-do-deic.shtml. Acesso em 17 de agosto de 2017.

FOWLER, Marcos Bittencourt. Criminalização dos movimentos sociais. Boletim Informativo do Instituto de Pesquisa Jurídica Bonijuris, vol. 4I3, p. 5.322-5.3।9, jun./2000.

GALEANO, Eduardo. As veias abertas da América Latina. Trad. Galeano Freitas. Rio de Janeiro: Paz e Terra, 2006.

GIAMBERARDINO, José. Criminalização dos movimentos sociais. In MERLIN CLÈVE, Clemerson (Org.). Direito constitucional brasileiro. Vol. I: teorias da constituição e direitos fundamentais. Rio de Janeiro: Revista dos Tribunais, 2014. 
GOHN, Maria da Glória. 500 anos de lutas sociais no Brasil: movimentos sociais, ONGs e Terceiro Setor. Revista Mediações, Londrina, v.5, n I, p. I I-40, jan./jun. 2000.

. Teoria dos Movimentos Sociais: paradigmas clássicos e contemporâneos. São Paulo: Loyola, 1997.

IBCCRIM. INSTITUTO BRASILEIRO DE CIENNCIAS CRIMINAIS. Editorial - As manifestações da sociedade civil e a repressão policial. Boletim IBCCRIM, São Paulo, v. 21 , n. 249, p. I, ago. 2013.

IHERING, Rudolf Von. A Luta pelo direito. São Paulo: Centauro, 2009.

INSTITUTO BRASILEIRO DE CIÊNCIAS CRIMINAIS (IBCCRIM). Disponível em https://www.ibccrim.org.br/boletim_artigo/4922-Editorial-As-manifestacoes-dasociedade-civil-e-a-repressao-policial. Ácesso em 17 de agosto de 2017.

MACRUZ, Beatriz e Outros. Disponível em http://diplomatique.org.br/o-estadobrasileiro-contra-os-movimentos-sociais/. Acesso em 17 de agosto de 2017.

MORAES, Luciana Simas Chaves de. A criminalização de movimentos sociais na Revolta do Vinagre. Boletim IBCCRIM, São Paulo, v. 2 I , n. 25 I , p. 4., out. 2013.

MOURA MASIERO, Clara. Movimentos sociais e política criminal no Brasil: entre a promoção de direitos e o punitivismo. Revista de Estudos Criminais, Porto Alegre, v. 10, n. 45, p. 143-164, abr./jun. 2012.

MOVIMENTO NACIONAL DE DIREITOS HUMANOS. Disponível em http://www.dhnet.org.br/dados/relatorios/r_mndh/r_mndh_criminalizacao_mov_soci ais.pdf. Acesso em 17 de agosto de 2017.

NOBRE, Marcos (Org.). Curso livre de teoria crítica. Campinas: Papirus, 2008.

OLIVEIRA, Bruno Almeida de. A proibição do uso de máscaras em manifestações públicas: subversão do programa garantista no país da pretensão democrática. Revista Liberdades, São Paulo, n. 2 I , p. I I0- I20, jan./abr. 2016.

PEDROSO, Regina Célia. Estado autoritário e ideologia policial. São Paulo: Humanitas, 2005. 
PEREIRA, Marcus Abilio Gomes. Movimentos sociais e democracia: a tensão necessária. Opinião Pública, Campinas, SP, v. I8, n. I , p. 68-87, out. 20I 5, p. 79. Disponível em: http://periodicos.sbu.unicamp.br/ojs/index.php/op/article/view/8641398. Acesso em 6 dez. 2015.

PINASSI, Maria Orlanda. Uma ontologia dos movimentos sociais de massas e o protaganismo atual das mulheres. Revista Pegada, vol. 9, n.2, p. I-I2, dez. 2008. Disponível em: http://revista.fct.unesp.br/index.php/pegada/article/view/I675/16।3. Acesso em: 6 dez. 2015.

PRADO, Geraldo et al. Aspectos contemporâneos da criminalização dos movimentos sociais no Brasil. Revista Brasileira de Ciências Criminais, São Paulo, v. 23, n. I I 2, p. 245-260, jan./fev. 2015.

REVISTA FÓRUM. Disponível em Fonte: http://www.revistaforum.com.br/wpcontent/uploads/20 |4/06/deic I - I.jpg e http://www.revistaforum.com.br/wpcontent/uploads/20 | 4/06/deic.jpg. Acesso em I ${ }^{\circ}$ de março de 2017.

SANTOS, Juarez Cirino dos. Direito Penal: Parte Geral. Florianópolis: Conceito Editorial, 2010.

SCHERER- WARREN, Ilse. Das mobilizações às redes de movimentos sociais. Revista Sociedade e Estado, Brasília, v. 2 I , n. I, p. I09- I 30, jan./abr. 2006.

- Manifestações de rua no Brasil 2013: encontros e desencontros na política. Cad. CRH. 20|4, vol.27, n.7।, p.4l7-429. Disponível em: <http://www.scielo.br/pdf/ccrh/v27n7l/al2v27n7l .pdf>. Acesso em: 6 dez. 20 I 5.

SILVA FILHO, José Carlos Moreira da. Criminologia e alteridade: o problema da criminalização dos movimentos sociais no Brasil. Revista de Estudos Criminais, Porto Alegre, v. 8, n. 29, p. 59-64., abr./jun. 2008.

Criminologia e alteridade: o problema da criminalização dos movimentos sociais no Brasil. In GAUER, Ruth Maria Chittó. Criminologia e sistemas jurídicopenais contemporâneos. Porto Alegre: EDIPUCRS, 20 I l.

SILVA, Ilse Gomes. Democracia e criminalização dos movimentos sociais no Brasil: as manifestações de junho de 2013 . Revista de Políticas Públicas, São Luís, v. 19 , n 2, p. 393-402, jul/dez de 2015. Disponível em: http://www.periodicoseletronicos. ufma.br/index.php/rppublica/article/download/43 I5/3957>. Acesso em 2/3/20 17. 
SPRESSOSP. Disponível em http://spressosp.com.br/20 I 4/06/26/inquerito-black-blocinterrogatorio-revela-conducao-politica-deic/. Acesso em 17 de agosto de 2017.

TOURAINE, Alain. O que é democracia. Petrópolis: Vozes, 2006.

TUFANO, Thiago. Disponível em https://noticias.terra.com.br/brasil/policia/sspanuncia-forca-tarefa-em-protestos-e-volta-de-balas-deborracha, I If5a7d3aa99 | 4 I OVgnVCM3000009acceb0aRCRD.html. Acesso em 17 de agosto de 2017.

VIOLA, Solon Eduardo Annes. Direitos humanos e democracia no Brasil. São Leopoldo: Unisinos, 2008.

. PIRES, Thiago Vieira. Os difíceis ecos dos direitos humanos: participação e cultura entre as gerações. Revista Debates, Porto Alegre, v. 8, n. 2, p. 83-102, maio/ago. 2014.

WOLKMER, Antônio Carlos. Movimentos sociais: nova fonte de juridicidade. Revista Direito Debate, v. 5, n. 7, Universidade ljuí, p. 47-50, jan.jun. 1996, p. 48. Disponível em: <https://www.revistas.unijui.edu.br/index.php/revistadireitoemdebate/article/ view/872/589> . Acesso em: 2 dez. 2015.

YAMAUTI, Nilson Nobuaki. O significado político de movimentos sociais que buscam interferir em decisões de governo concernentes à alocação de recursos públicos. Acta Scientiarum, Maringá, v. 23, p. 24I-249, 2001. Disponível em: $<$ http://periodicos.uem.br/ojs/index.php/ActaSciHumanSocSci/article/view/2797/190 5.> Acesso em: 6 dez. 2015.

ZAFFARONI, Eugenio Raúl; Pierangeli, José Henrique. Manual de direito penal brasileiro. São Paulo: RT, 201 l .

Recebido em: 14/06/2017

Aprovado em: 28/06/2017 
